\title{
A Role for Matrix Metalloproteases in Antidepressant Efficacy
}

\author{
Seham Alaiyed ${ }^{1}$ and Katherine Conant ${ }^{2 *}$ \\ ${ }^{1}$ Department of Pharmacology, Georgetown University Medical Center, Washington, DC, United States, ${ }^{2}$ Department of \\ Neuroscience, Georgetown University Medical Center, Washington, DC, United States
}

Major depressive disorder is a debilitating condition that affects approximately $15 \%$ of the United States population. Though the neurophysiological mechanisms that underlie this disorder are not completely understood, both human and rodent studies suggest that excitatory/inhibitory (E/I) balance is reduced with the depressive phenotype. In contrast, antidepressant efficacy in responsive individuals correlates with increased excitatory neurotransmission in select brain regions, suggesting that the restoration of E/I balance may improve mood. Enhanced excitatory transmission can occur through mechanisms including increased dendritic arborization and synapse formation in pyramidal neurons. Reduced activity of inhibitory neurons may also contribute to antidepressant efficacy. Consistent with this possibility, the fast-acting antidepressant ketamine may act by selective inhibition of glutamatergic input to GABA releasing parvalbumin (PV)-expressing interneurons. Recent work has also shown that a negative allosteric modulator of the GABA-A receptor a subunit can improve depression-related behavior. PV-expressing interneurons are thought to represent critical pacemakers for synchronous network events. These neurons also represent the predominant GABAergic neuronal population that is enveloped by the

OPEN ACCESS

Edited by: Enrico Tongiorgi, University of Trieste, Italy

Reviewed by:

Rochelle Marie Hines, University of Nevada, Las Vegas, United States

Richard J. Weinberg, The University of North Carolina at Chapel Hill, United States

*Correspondence: Katherine Conant kec84@georgetown.edu

Received: 15 October 2018 Accepted: 24 April 2019 Published: 08 May 2019

Citation: Alaiyed S and Conant K (2019) A Role for Matrix Metalloproteases

in Antidepressant Efficacy.

Front. Mol. Neurosci. 12:117. doi: 10.3389/fnmol.2019.00117 perineuronal net (PNN), a lattice-like structure that is thought to stabilize glutamatergic input to this cell type. Disruption of the PNN reduces PV excitability and increases pyramidal cell excitability. Various antidepressant medications increase the expression of matrix metalloproteinases (MMPs), enzymes that can increase pyramidal cell dendritic arborization and spine formation. MMPs can also cleave PNN proteins to reduce PV neuron-mediated inhibition. The present review will focus on mechanisms that may underlie antidepressant efficacy, with a focus on monoamines as facilitators of increased matrix metalloprotease (MMP) expression and activation. Discussion will include MMPdependent effects on pyramidal cell structure and function, as well as MMP-dependent effects on PV expressing interneurons. We conclude with discussion of antidepressant use for those at risk for Alzheimer's disease, and we also highlight areas for further study.

Keywords: matrix metalloproteases, perineuronal nets, depression, monoamines, gamma oscillations

\section{INTRODUCTION}

Major depression is a life-threatening disorder that imparts substantial pain and suffering on affected individuals as well as their friends and family members. First-line therapy typically involves the use of specific monoamine reuptake inhibitors. While these drugs are effective in a subset of patients, for other patients they have little to no benefit. An improved understanding of the 
molecular and neurophysiological mechanisms that contribute to improved mood in responsive individuals could drive the development of novel drugs or drug combinations. The present review is focused on the potential for increased MMP activity to contribute to antidepressant efficacy. We also discuss the possibility that pre-emptive use of monoamine reuptake inhibitors that increase MMP activity could benefit patients who are likely to develop Alzheimer's disease, a disorder for which untreated major depression is a significant risk factor.

\section{MAJOR DEPRESSION IS LINKED TO REGIONAL REDUCTIONS IN BRAIN VOLUME AND ATTENUATED GLUTAMATERGIC TRANSMISSION}

In a human study, hippocampal volume was reduced in association with depression and increased in association with a therapeutic response to antidepressant therapy (Joshi et al., 2015). Moreover, in a large consortium analysis spanning 200 institutions in 35 countries, human hippocampal volume was reduced with major depression (Thompson P.M. et al., 2015). The magnitude of hippocampal volume reduction has also been linked to disease duration (Kessing and Nilsson, 2003). In a recent meta-analysis, increased hippocampal volume was identified as the most promising marker for disease remission in response to antidepressant treatment (Chi et al., 2015). In rodent models both electroconvulsive therapy and imipramine have been shown to increase hippocampal volume (Chen et al., 2008, 2009, 2010). In contrast, in an unpredictable stress-induced model of depression hippocampal volume is reduced (Schoenfeld et al., 2017).

It has been suggested that anti-depressant therapy might increase hippocampal volume through the generation of new neurons as well as through specific structural changes in dendrites of pre-existing neurons (Chen et al., 2008, 2009, 2010). The latter effect may be of particular importance to treatment efficacy, since increased dendritic branching and formation of new dendritic spines would allow for an increase in the number of post-synaptic contacts for glutamate. Structural analyses suggest that the large majority of inputs to the dendrites of glutamatergic neurons are excitatory (Kasthuri et al., 2015), and functional studies have linked increased dendritic arbor with an increased neuronal calcium response (He et al., 2016).

Glutamatergic transmission is indeed reduced with depression (Kuhn et al., 2016). Various human and rodent studies suggest that depression is linked to reductions in the overall strength of glutamatergic transmission in the hippocampus [reviewed in Thompson S.M. et al. (2015)]. Published work has also demonstrated an association between stress and reduced mRNA for the glutamate receptor subunit GluA1 within the hippocampus, as well as impaired long-term potentiation (LTP) of synaptic transmission (Alfarez et al., 2003; Schmidt et al., 2010). Moreover, autopsy studies have shown that multiple glutamate receptor subunits are reduced in patients that were diagnosed with depression (Choudary et al., 2005; Beneyto et al., 2007).
Agents that enhance monoaminergic transmission can stimulate dendritic branching and spine formation in various neuronal subtypes. For example, one study showed that the number of spines on excitatory neurons was increased in the hippocampus following 14 days of treatment with imipramine as compared to saline (Chen et al., 2008). Imipramine also enhances the complexity of immature neurons in the granule cell layer (Fenton et al., 2015) while methamphetamine and cocaine increase dendritic arbor and spine number in striatum (Robinson and Kolb, 2004). Furthermore, the noradrenergic and serotonergic tetracycline antidepressant mirtazapine can increase dendritic arbor in the sensory cortex of MeCP2 null mice (Bittolo et al., 2016).

Monoamines have also been shown to enhance hippocampal neurogenesis (Jhaveri et al., 2010), though whether newborn neurons influence excitatory/inhibitory balance in a widespread manner is unclear. Work from Duman and colleagues has shown that antidepressant therapies including the selective serotonin reuptake inhibitor (SSRI) fluoxetine can enhance neurogenesis in the adult rat hippocampus, and that this effect requires chronic (14 days) as opposed to acute treatment (Malberg et al., 2000). In terms of therapeutic relevance, neurogenesis in the adult hippocampus is important for the antidepressant fluoxetine to prevent stress-induced anhedonia in rodents (Miller and Hen, 2015), and newborn neurons also reduce the activity of stress-responsive neurons in the ventral dentate gyrus (Anacker et al., 2018).

\section{INCREASED MATRIX METALLOPROTEASE ACTIVITY MIGHT AMELIORATE DEPRESSION-RELATED CHANGES IN BRAIN STRUCTURE AND FUNCTION}

\section{An Introduction to Matrix Metalloproteases}

Matrix metalloproteases (MMPs) are zinc-dependent endopeptidases that are typically released as pro-forms from intracellular stores. Extracellular activation is generally achieved through cleavage of the pro-domain which exposes the catalytic region. Pro-domain cleavage is mediated by previously activated MMPs and by additional proteases including plasmin (Baramova et al., 1997; Toth et al., 2003). Cleavage-independent changes in tertiary structure that allow for exposure of the catalytic domain may also follow from nitrosylation and alternative oxidationdependent effects on cysteine residues (Okamoto et al., 2001; Gu et al., 2002).

Though more than 20 MMP family members are expressed in humans, a select subset is expressed by resident cells of the central nervous system. These include MMP-2, which can be released from astrocytes and microglia, and MMP-9 which can be released from neurons and microglia (Conant et al., 2015). MMP-1 and MMP-3 are also released from neurons and glia and, along with MMP-2 and MMP-9, these family members have been implicated in structural and functional changes that enhance learning and 
memory (Meighan et al., 2006; Nagy et al., 2006; Almonte et al., 2013; Lonskaya et al., 2013; Wojtowicz and Mozrzymas, 2014; Allen et al., 2016; Wiera et al., 2017).

Matrix metalloproteases cleave a variety of substrates. Pathologically elevated levels of MMPs, or dysregulated localization of release, can contribute to neuronal injury (Asahi et al., 2000). Release occurring at physiologically appropriate levels, with localized proteolysis of specific substrates, is instead critical to neuroplasticity (Huntley, 2012; Sonderegger and Matsumoto-Miyai, 2014; Conant et al., 2015). Plasticity-relevant substrates include trans-synaptic adhesion molecules (Lonskaya et al., 2013), protease-activated G protein coupled receptors (Allen et al., 2016), and components of the perineuronal net (PNN) (Huntley, 2012; Sonderegger and Matsumoto-Miyai, 2014; Conant et al., 2015; Bozzelli et al., 2018).

\section{MMP Activity Contributes to Neuronal Arborization, Dendritic Spine Expansion, and Enhanced Learning and Memory}

Several MMPs have been associated with enhanced dendritic arborization. For example, exogenous MMP-1 increases arborization of cultured murine hippocampal neurons and astrocyte-driven overexpression of human MMP-1 increases dendritic arborization in murine cortex as determined by Golgi staining and analysis (Allen et al., 2016). Conversely, MMP-2 deletion reduces dendritic arbor in cerebellar Purkinje cells, MMP-3 deletion reduces dendritic arbor in the visual cortex (Aerts et al., 2015; Verslegers et al., 2015), and MMP-9 deletion reduces both dendritic length and complexity in pyramidal neurons of the murine CA1 hippocampus (Murase et al., 2016). In related work, broad-spectrum MMP inhibitors have been shown to reduce neurite outgrowth in cultured cortical neurons (Sanz et al., 2015).

In terms of the potential to influence hippocampal function in a relatively rapid manner, MMPs have been shown to stimulate formation of spine head protrusions (Szepesi et al., 2013) and to increase the width or length of spines or their precursors (Tian et al., 2007; Wang et al., 2008; Stawarski et al., 2014). MMPgenerated integrin binding ligands can also increase surface levels of dendritic GluA1 and can increase the frequency of mini excitatory post-synaptic currents, perhaps secondary to synaptic unsilencing (Lonskaya et al., 2013).

Consistent with their ability to quickly enhance synaptic plasticity, MMP-3 and -9 activity have been linked to longterm potentiation (LTP) of synaptic transmission in hippocampal regions (Nagy et al., 2006; Meighan et al., 2007; Conant et al., 2010; Wiera et al., 2017). LTP, one of the functional underpinnings of learning and memory, is reduced in models of depression (Riga et al., 2017) and its expression depends on the expansion and/or formation of dendritic spines. MMP-2 and -9 activity also enhance learning and memory in other regions including the striatum and the amygdala (Ganguly et al., 2013; Smith et al., 2014).

Though a full understanding of the mechanisms that underlie MMP-dependent neuroplasticity is not complete, several nonexclusive mechanisms have been described. These include generation of integrin binding ligands and integrin-dependent actin polymerization and spine expansion, cleavage-dependent activation of specific $\mathrm{G}$ protein coupled receptors, and activation of pro-neurotrophins (Lee et al., 2001; Conant et al., 2015). Integrin signaling, however, appears critical to MMP-dependent dendritic spine expansion (Nagy et al., 2006; Meighan et al., 2007; Wang et al., 2008; Lonskaya et al., 2013).

\section{MMP Activity May Contribute to Pyramidal Cell Disinhibition}

An overall reduction in excitatory to inhibitory balance could follow from changes restricted to pyramidal cells. Emerging evidence, however, also supports a role for disinhibition of pyramidal cells as a potential mediator of antidepressant efficacy. Consistent with this, ketamine, which preferentially targets NMDA-responsive glutamate receptors on GABAergic interneurons (Widman and McMahon, 2018), can alleviate depression-related behavior in a rapid and sustained manner (Zarate et al., 2006). An allosteric modulator of a GABA A receptor subunit can similarly alleviate behavioral manifestations of depression (Zanos et al., 2017). Less directly, changes to perineuronal net (PNN) integrity might also promote pyramidal cell disinhibition (Frischknecht et al., 2009; Slaker et al., 2015; Favuzzi et al., 2017; Hayani et al., 2018). Several studies suggest that attenuation of the PNN may reduce PV interneuron activity, leading to pyramidal cell disinhibition. Without an intact PNN, glutamate may more easily diffuse from presynaptic release sites (Bikbaev et al., 2015). PNN disruption has also been linked to enhanced lateral diffusion of glutamate receptors on $\mathrm{PV}$ interneurons so that receptors are less well positioned to receive glutamate input (Frischknecht et al., 2009). Moreover, PNN disruption can increase membrane capacitance and thus reduce the ability of PV interneurons to fire (Tewari et al., 2018). Consistent with these studies, the frequency of mini excitatory post-synaptic potentials (mEPSCs) recorded from PV expressing fast spiking interneurons is reduced in mice that do not express brevican, an important PNN component (Favuzzi et al., 2017). In addition, PNN disruption observed 7 days after the administration of chondroitinase is associated with a reduction in both spontaneous and mini EPSCs recorded from PV interneurons (Hayani et al., 2018).

The potential for antidepressant medications to effect disinhibition is supported by rodent studies linking monoamine reuptake inhibitors to reductions in PNN integrity (Ohira et al., 2013; Guirado et al., 2014; Umemori et al., 2015). This could follow from the ability of monoamine reuptake inhibitors to increase expression of PNN-degrading proteases including MMP-9 (Tamasi et al., 2014; Murase et al., 2017; Wen et al., 2017). In a recent study, the serotonin and norepinephrine reuptake inhibitor venlafaxine increased hippocampal levels of MMP-9 protein and attenuated PNN expression (Alaiyed et al., 2019). In contrast, in a social defeat stress model, the depressive phenotype was associated with increased levels of PNN components (Riga et al., 2017). Work that examined the effects of social isolation, which also induces a depressive phenotype, demonstrated increases in PNNs in select regions of the amygdala and 
prefrontal cortex (Castillo-Gomez et al., 2017). In human work, changes in PNN staining have been noted with depression (Pantazopoulos and Berretta, 2016), and a polymorphism in the PNN constituent neurocan has been associated with increased risk of bipolar depression (Cichon et al., 2011).

Parvalbumin (PV)-expressing cells are the predominant GABA-releasing neuronal population that is surrounded by the PNN (Pizzorusso et al., 2002; Rossier et al., 2015; Lensjo et al., 2017a). Since each PV interneuron can contact hundreds of pyramidal cells (Andersen et al., 2006), PNN disruption may influence pyramidal cell activity at the population level. Consistent with this, recent findings in rodents show that PNN diminution has the potential to enhance both the power of gamma oscillations and the frequency of sharp wave ripple events (Lensjo et al., 2017b; Sun et al., 2018). Similarly, chronic venlafaxine treatment stimulates PNN diminution and an MMP-9-dependent increase in carbachol-induced gamma oscillatory power in ex vivo hippocampal slices (Alaiyed et al., 2019). While the activity of PV-expressing cells contributes to both sharp wave ripples and gamma oscillations, disinhibition of pyramidal cell activity can also influence these events. Pyramidal cell-derived sharp wave magnitude correlates with gamma power, and sharp waves initiate the sharp wave ripple complex (Sullivan et al., 2011). Importantly, gamma oscillations and sharp wave ripples are critical to memory encoding and consolidation (Buzsaki, 1989; Howard et al., 2003; Jutras and Buffalo, 2010), processes that may go awry in the setting of depression (MacQueen and Frodl, 2011).

Gamma oscillations associated with exercise and sharp wave ripples associated with sleep or quite restfulness are typically mutually exclusive, but the two rhythms are not fully independent. Recent work shows that exercise-induced enhancement of theta-nested gamma oscillations can stimulate a subsequent increase in sharp wave ripple area as detected with in vivo recordings (Zarnadze et al., 2016). Similarly, in ex vivo hippocampal slices, carbachol and kainate stimulated gamma oscillations are associated with a post-washout enhancement of sharp wave ripple area and event frequency (Zarnadze et al., 2016).

While future studies will be necessary to better elucidate the role of PNN modulation as a means to stimulate an increase in gamma oscillation power in humans, the potential significance of gamma to major depression is underscored in a recent review that focused on abnormalities in this rhythm as a potential biomarker of disease (Fitzgerald and Watson, 2018). Importantly, the power of gamma oscillations could represent a measurable correlate of monoamine and MMP-dependent enhancement of E/I balance.

\section{A BETTER UNDERSTANDING OF ANTIDEPRESSANT-ASSOCIATED INCREASES IN MMP EXPRESSION COULD LEAD TO NOVEL THERAPEUTICS}

Currently available antidepressants have the potential to increase excitatory neurotransmission. Several lines of evidence link both enhanced excitatory transmission and glutamate receptor activation to increased MMP expression or release (Michaluk et al., 2007; Pauly et al., 2008; Conant et al., 2010; Wiera et al., 2012). In neurons, glutamate can stimulate increased DNA binding of AP-1 with subsequent rapid expression of MMP9 (Bajor et al., 2012; Kuzniewska et al., 2013). In addition, pre-formed MMPs are observed in perisynaptic intra-vesicular stores (Sbai et al., 2008). Release of vesicular MMPs from non-neural cells is soluble NSF attachment protein receptor (SNARE) dependent (Kean et al., 2009); if a similar mechanism occurs in neurons and glia, MMP release might be facilitated by stimuli such as glutamate that can evoke increases in intracellular calcium.

Though the effects of monoamines on MMP release from brain cells have been less extensively studied, noradrenaline increases MMP-2 and MMP-9 activity in a hypothalamic slice preparation (Maolood et al., 2008). In striatal slice preparations (Li et al., 2016), dopamine and a D1 receptor agonist can upregulate MMP activity, as determined by an increase in MMPdependent cleavage of $\beta$-dystroglycan. In non-neural cells, several studies suggest that monoamines can enhance MMP expression as well as MMP-dependent endpoints (Rietz and Spiers, 2012). For example, norepinephrine upregulates the expression of MMP-2 and MMP-9 in cultured nasopharyngeal carcinoma cells (Yang et al., 2006). Moreover, published work suggests that norepinephrine-induced remodeling of rat heart is MMP dependent (Briest et al., 2001).

Specific transcription factors may underlie monoamine dependent changes in MMP expression. We have observed that norepinephrine can increase DNA binding activity of AP-1 in brain-derived cells (Conant et al., 2004). CREB may also influence MMP expression (Xie et al., 1997), and this transcription factor is relevant to effects of monoaminergic antidepressants (Chen et al., 2001). $\beta$ adrenergic receptors and $5-\mathrm{HT}_{7}$ serotonin receptors are typically linked to Gas signaling and therefore likely activate CREB (Shaywitz and Greenberg, 1999). Consistent with this are studies linking the 5- $\mathrm{HT}_{7}$ receptor to increased MMP-9 activity (Bijata et al., 2017). Additional studies are warranted to fully identify transcription factors that link the activation of specific monoamine receptor subtypes and enhanced MMP expression.

Monoamine modulators including the serotonin/norepinephrine reuptake inhibitor venlafaxine have been associated with an increase in MMP-9 mRNA expression (Tamasi et al., 2014) and MMP-9 protein levels (Alaiyed et al., 2019). Moreover, psychostimulants that increase monoamine levels including methamphetamine and cocaine have been associated with increased MMP-2- and MMP-9-dependent neuroplasticity (Mizoguchi et al., 2007, 2008; Conant et al., 2011; Smith et al., 2014). In Figure 1, we show a hypothetical schematic of PNN and MMP changes in the brains of normal individuals, those with untreated depression, and those with depression who are taking a monoamine reuptake inhibitor. While stress and the depressive phenotype have been associated with an increase in PNN deposition in a rat model (Riga et al., 2017), and imipramine can normalize PNN levels and concomitantly improve LTP (Riga et al., 2017), additional study will be necessary to determine whether depression and stress increase PNN levels 


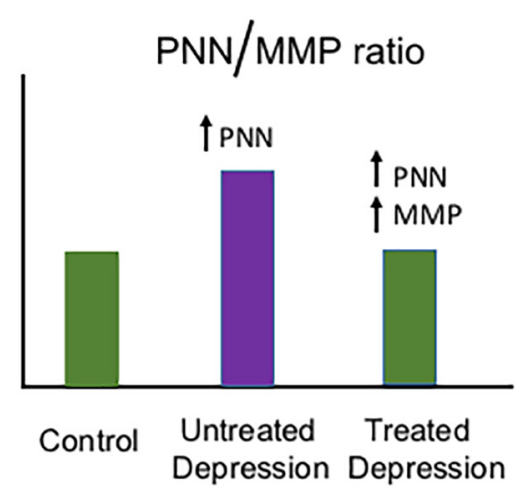

FIGURE 1 | Hypothetical model of depression-related changes in the PNN/MMP ratio. Shown is a hypothetical histogram of potential changes in the PNN/MMP ratio ( $Y$ axis) in brain tissue from control patients, untreated but depressed patients, and depressed patients treated with a monoamine reuptake inhibitor (grouped along the $X$ axis as indicated). Control patients have physiological PNN and MMP levels, while untreated patients with depression may have an increase in PNN deposition due to factors including stress (Riga et al., 2017) and thus an increase in the PNN/MMP ratio. In contrast, in depressed patients who are treated with monoamine reuptake inhibitors, MMP levels may increase and thus bring the PNN/MMP ratio back to control patient levels.

in humans and whether antidepressant treatment can restore an adaptive PNN/MMP balance.

\section{MMP MODULATION MAY BE USEFUL FOR ALZHEIMER'S DISEASE AND ADDITIONAL DISORDERS IN WHICH HIPPOCAMPAL DYSFUNCTION IS A PROMINENT FEATURE}

It is critical to identify effective strategies to reduce the incidence of Alzheimer's disease (AD), the most common form of dementia

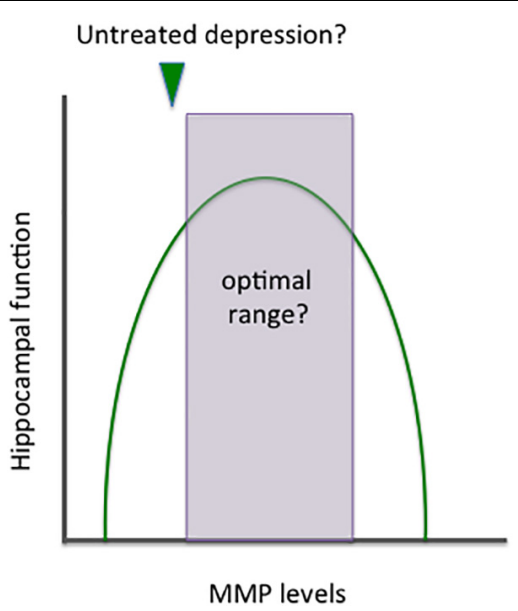

FIGURE 3 | Benefits and risks of altering MMP expression. MMPs target a variety of CNS substrates and thus it is not surprising that their activity has been implicated in both neuroprotection and neuronal injury. Similar to norepinephrine, these enzymes appear to have an inverted $U$ shaped curve with respect to benefit. Overall effects on plasticity likely depend not only on absolute levels but on MMP subtypes and cellular sources, as well as the location of their release. In depression, it may be of benefit to increase the expression of specific MMPs and/or shift overall levels to the right side of the area that remains within the inverted $U$ shape.

in individuals who are over age 65. Epidemiological studies suggest that education, social engagement, and exercise may reduce risk and/or delay the age of disease onset (Kivipelto et al., 2018). In contrast, untreated major depression can increase AD risk (Kivipelto et al., 2018).

Deficits in monoaminergic transmission have been implicated in the pathogenesis of Alzheimer's disease (AD). For example, tau lesions within the locus coeruleus (LC), the predominant source of norepinephrine within the CNS, are identified early in disease, occurring up to 10 years prior to the onset of cognitive symptoms (Chalermpalanupap et al., 2013). Importantly, LC lesions increase
A

\section{Older age}

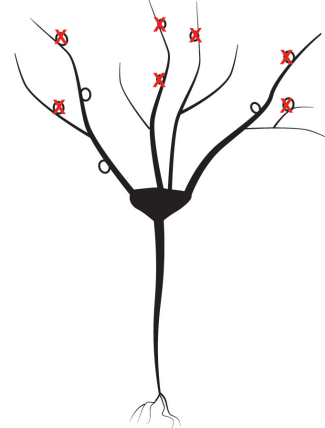

B

Older age + monoamines

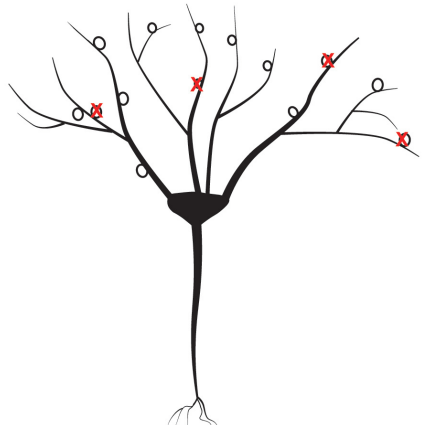

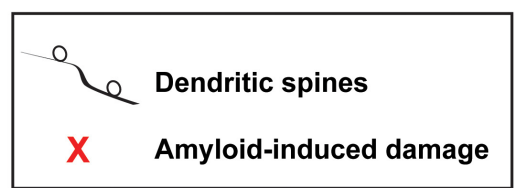

FIGURE 2 | Schematic showing hypothetical monoamine dependent effects on the aging brain. At left is a schematic showing a representative neuron with amyloid mediated synaptic injury in older age (A) and a neuron having more arbor and synapses, as well as lesser amounts of peri-neuronal amyloid, in older age developing in the background of monoamine reuptake inhibition (B). 
$\mathrm{A} \beta$ plaque load and spatial memory deficits in a mouse model of AD (Kalinin et al., 2007). In related work, enhanced serotonergic signaling is linked to reduced $A \beta$ deposition in human studies as well as in a murine model of AD (Sheline et al., 2014).

Importantly, both MMP-9 and the transmembrane spanning A Disintegrin and Metalloprotease-10 (ADAM-10) have been shown to act as $\alpha$ secretases (Jorissen et al., 2010; Fragkouli et al., 2012), which process amyloid precursor protein (APP) so that amyloid aggregates do not form. In a mouse model of AD, MMP-9 overexpression is neuroprotective (Fragkouli et al., 2014). In related work, overexpression of MMP-2, which shares considerable overlap in substrate specificity with MMP-9 but is typically less inducible, nearly abolished toxic amyloid$\beta$ production in HEK cells that overexpressed hAPP (Py et al., 2014). Furthermore, tissue inhibitor of matrix metalloprotease3, which inhibits both ADAMs and soluble MMPs including MMP-9 (Brew and Nagase, 2010), increases amyloid aggregatepromoting $\beta$ secretase-mediated processing of amyloid precursor protein (Hoe et al., 2007).

Based on work showing that conditional knockout of ADAM-10 in neural stem cells led to substantially reduced $\alpha$ secretase mediated processing of APP, it has been suggested that ADAM-10 represents the predominant brain-resident $\alpha$ secretase [(Jorissen et al., 2010); see also related work in Lammich et al. (1999), Skovronsky et al. (2000), Hartmann et al. (2002)]. While ADAM-10 may be important to protein kinase C-activated cleavage (Skovronsky et al., 2000), increases in inducible MMPs such as MMP-9 may upregulate $\alpha$ cleavage in select settings. This is supported by work showing $\alpha$ secretase activity is maintained in the majority of cell lines derived from embryonic ADAM-10 deficient fibroblasts (Hartmann et al., 2002). Intriguingly, ADAM-10 knockdown substantially reduces MMP-9 levels (Li et al., 2015; van der Vorst et al., 2015). Of additional interest, select agonists for the $\mathrm{G}$ protein coupled protease activated receptor1, which include MMPs, can increase ADAM-10 activity (Li et al., 2014).

Consistent with the potential of monoamines to enhance metalloprotease (MP) dependent APP processing, one group retrospectively compared brain amyloid load in elderly patients that were exposed to antidepressant drugs within the previous 5 years to control patients that were not (Sheline et al., 2014). Antidepressant-exposed individuals had substantially less amyloid load as quantified by positron emission tomography (PET) imaging. Intriguingly, cumulative time of antidepressant use within the period of interest correlated with a reduction in plaque load. Chronic treatment with the SSRI citalopram reduced plaque burden in mice, and related work suggested that serotonin could increase $\alpha$ secretase activity (Cirrito et al., 2011). Interestingly this effect is ERK-dependent, and ERK signaling has been linked to increased expression of both MMP-9 and ADAM-10 (Wan et al., 2012; Missan et al., 2015). Treatment of rodents with citalopram, however, did not increase expression of ADAM-10 or neprilysin, another $\alpha$ secretase (Cirrito et al., 2011). Importantly, in addition to their potential to enhance cognitive reserve and non-amyloidogenic APP processing as discussed previously, MMPs including MMP-2 can directly cleave amyloid (Hernandez-Guillamon et al., 2015) to reduce plaque load. An overview of mechanisms by which MMP activity could enhance cognitive reserve and reduce amyloid accumulation in individuals at risk for AD is diagrammed in Figure 2.

Metalloproteinases target varied CNS substrates, and MMPs can thus enhance adaptive brain plasticity or stimulate inflammation and cytotoxicity. Though the location of release is also important, MMPs may have an inverted $U$ shaped curve with respect to overall levels and benefit (see Figure 3).

\section{SUMMARY AND FUTURE DIRECTIONS}

In summary, an appreciable body of evidence has emerged to suggest that major depressive disorder is linked to disrupted excitatory neurotransmission. This can follow from changes including reduced neuronal arborization and synapse formation as well as increased PNN deposition (Thompson S.M. et al., 2015; Riga et al., 2017). If untreated, these changes can predispose an individual to depression and/or an increased risk of dementia.

Future studies will be necessary to examine critical questions including whether MMPs contribute to behavioral improvement in depression or animal models, and whether potential changes to gamma oscillatory power or sharp wave ripple event frequency will be adaptive. With respect to this latter issue, it will be necessary to determine whether monoamine reuptake inhibitors and/or MMPs will lead to reactivation of learning-activated neuronal assemblies during sharp wave ripple events.

Finally, future studies should further explore the possibility that select antidepressants, alone or in or combination, will reduce or ameliorate Alzheimer's pathology/symptomatology. This could follow from slowly evolving enhancement of cognitive reserve and reduced amyloid deposition. In addition, improved cognition in the short term could follow from PNN modulation with subsequently enhanced SWR frequency and/or gamma power (Insel et al., 2012; Iaccarino et al., 2016; Klein et al., 2016; Cattaud et al., 2018; Cowen et al., 2018; Stoiljkovic et al., 2018).

\section{AUTHOR CONTRIBUTIONS}

SA and KC wrote and revised the portions of this review.

\section{FUNDING}

SA received support from the Saudi Arabian Government, Qassim University scholarship program, and KC received funds for support and supplies from Deborah Wilson and Anthony Herman through the Georgetown University Partners in Research program.

\section{ACKNOWLEDGMENTS}

We would like to acknowledge P. Lorenzo Bozzelli for assistance with figure preparation. 


\section{REFERENCES}

Aerts, J., Nys, J., Moons, L., Hu, T. T., and Arckens, L. (2015). Altered neuronal architecture and plasticity in the visual cortex of adult MMP-3-deficient mice. Brain Struct. Funct. 220, 2675-2689. doi: 10.1007/s00429-014-0819-4

Alaiyed, S., Bozzelli, P. L., Caccavano, A., Wu, J. Y., and Conant, K. (2019). Venlafaxine stimulates PNN proteolysis and MMP-9-dependent enhancement of gamma power; relevance to antidepressant efficacy. J. Neurochem. 148, 810-821. doi: 10.1111/jnc. 14671

Alfarez, D. N., Joels, M., and Krugers, H. J. (2003). Chronic unpredictable stress impairs long-term potentiation in rat hippocampal CA1 area and dentate gyrus in vitro. Eur. J. Neurosci. 17, 1928-1934. doi: 10.1046/j.1460-9568.2003.02622.x

Allen, M., Ghosh, S., Ahern, G. P., Villapol, S., Maguire-Zeiss, K. A., and Conant, K. (2016). Protease induced plasticity: matrix metalloproteinase-1 promotes neurostructural changes through activation of protease activated receptor 1 . Sci. Rep. 6:35497. doi: 10.1038/srep35497

Almonte, A. G., Qadri, L. H., Sultan, F. A., Watson, J. A., Mount, D. J., Rumbaugh, G., et al. (2013). Protease-activated receptor-1 modulates hippocampal memory formation and synaptic plasticity. J. Neurochem. 124, 109-122. doi: 10.1111/jnc. 12075

Anacker, C., Luna, V. M., Stevens, G. S., Millette, A., Shores, R., Jimenez, J. C., et al. (2018). Hippocampal neurogenesis confers stress resilience by inhibiting the ventral dentate gyrus. Nature 559, 98-102. doi: 10.1038/s41586-018-0262-4

Andersen, P., Morris, R., Amaral, D., Bliss, T., and O'Keefe, J. (eds). (2006). The Hippocampus Book. New York, NY: Oxford University Press.

Asahi, M., Asahi, K., Jung, J.-C., del Zoppo, G. J., Fini, M. E., and Lo, E. H. (2000). Role for matrix metalloproteinase 9 after focal cerebral ischemia: effects of gene knockout and enzyme inhibition with BB-94. J. Cereb. Blood Flow Metab. 20, 1681-1689. doi: 10.1097/00004647-200012000-00007

Bajor, M., Michaluk, P., Gulyassy, P., Kekesi, A. K., Juhasz, G., and Kaczmarek, L. (2012). Synaptic cell adhesion molecule-2 and collapsin response mediator protein-2 are novel members of the matrix metalloproteinase- 9 degradome. J. Neurochem. 122, 775-788. doi: 10.1111/j.1471-4159.2012.07829.x

Baramova, E. N., Bajou, K., Remacle, A., L'hoir, C., Krell, H. W., Weidle, U. H., et al. (1997). Involvement of PA/plasmin system in the processing of pro-MMP9 and in the second step of pro-MMP-2 activation. FEBS Lett. 405, 157-162. doi: 10.1016/s0014-5793(97)00175-0

Beneyto, M., Kristiansen, L. V., Oni-Orisan, A., Mccullumsmith, R. E., and Meador-Woodruff, J. H. (2007). Abnormal glutamate receptor expression in the medial temporal lobe in schizophrenia and mood disorders. Neuropsychopharmacology 32, 1888-1902. doi: 10.1038/sj.npp.1301312

Bijata, M., Labus, J., Guseva, D., Stawarski, M., Butzlaff, M., Dzwonek, J., et al. (2017). Synaptic remodeling depends on signaling between serotonin receptors and the extracellular matrix. Cell Rep. 19, 1767-1782. doi: 10.1016/j.celrep.2017. 05.023

Bikbaev, A., Frischknecht, R., and Heine, M. (2015). Brain extracellular matrix retains connectivity in neuronal networks. Sci. Rep. 5:14527. doi: 10.1038/ srep 14527

Bittolo, T., Raminelli, C. A., Deiana, C., Baj, G., Vaghi, V., Ferrazzo, S., et al. (2016). Pharmacological treatment with mirtazapine rescues cortical atrophy and respiratory deficits in MeCP2 null mice. Sci. Rep. 6:19796. doi: 10.1038/ srep19796

Bozzelli, P. L., Alaiyed, S., Kim, E., Villapol, S., and Conant, K. (2018). Proteolytic remodeling of perineuronal nets: effects on synaptic plasticity and neuronal population dynamics. Neural Plast. 2018:5735789. doi: 10.1155/2018/5735789

Brew, K., and Nagase, H. (2010). The tissue inhibitors of metalloproteinases (TIMPs): an ancient family with structural and functional diversity. Biochim. Biophys. Acta 1803, 55-71. doi: 10.1016/j.bbamcr.2010.01.003

Briest, W., Holzl, A., Rassler, B., Deten, A., Leicht, M., Baba, H. A., et al. (2001). Cardiac remodeling after long term norepinephrine treatment in rats. Cardiovasc. Res. 52, 265-273. doi: 10.1016/s0008-6363(01)00398-4

Buzsaki, G. (1989). Two-stage model of memory trace formation: a role for "noisy" brain states. Neuroscience 31, 551-570. doi: 10.1016/0306-4522(89)90423-5

Castillo-Gomez, E., Perez-Rando, M., Belles, M., Gilabert-Juan, J., Llorens, J. V., Carceller, H., et al. (2017). Early social isolation stress and perinatal NMDA receptor antagonist treatment induce changes in the structure and neurochemistry of inhibitory neurons of the adult amygdala and prefrontal cortex. eNeuro 4:ENEURO.0034-17.2017. doi: 10.1523/ENEURO.0034-17. 2017

Cattaud, V., Bezzina, C., Rey, C. C., Lejards, C., Dahan, L., and Verret, L. (2018). Early disruption of parvalbumin expression and perineuronal nets in the hippocampus of the Tg2576 mouse model of Alzheimer's disease can be rescued by enriched environment. Neurobiol. Aging 72, 147-158. doi: 10.1016/ j.neurobiolaging.2018.08.024

Chalermpalanupap, T., Kinkead, B., Hu, W. T., Kummer, M. P., Hammerschmidt, T., Heneka, M. T., et al. (2013). Targeting norepinephrine in mild cognitive impairment and Alzheimer's disease. Alzheimers Res. Ther. 5:21. doi: 10.1186/ alzrt175

Chen, A. C., Shirayama, Y., Shin, K. H., Neve, R. L., and Duman, R. S. (2001). Expression of the cAMP response element binding protein (CREB) in hippocampus produces an antidepressant effect. Biol. Psychiatry 49, 753-762. doi: 10.1016/s0006-3223(00)01114-8

Chen, F., Madsen, T. M., Wegener, G., and Nyengaard, J. R. (2008). Changes in rat hippocampal CA1 synapses following imipramine treatment. Hippocampus 18 , 631-639. doi: 10.1002/hipo.20423

Chen, F., Madsen, T. M., Wegener, G., and Nyengaard, J. R. (2009). Repeated electroconvulsive seizures increase the total number of synapses in adult male rat hippocampus. Eur. Neuropsychopharmacol. 19, 329-338. doi: 10.1016/j. euroneuro.2008.12.007

Chen, F., Madsen, T. M., Wegener, G., and Nyengaard, J. R. (2010). Imipramine treatment increases the number of hippocampal synapses and neurons in a genetic animal model of depression. Hippocampus 20, 1376-1384. doi: 10.1002/ hipo. 20718

Chi, K. F., Korgaonkar, M., and Grieve, S. M. (2015). Imaging predictors of remission to anti-depressant medications in major depressive disorder. J. Affect. Disord. 186, 134-144. doi: 10.1016/j.jad.2015.07.002

Choudary, P. V., Molnar, M., Evans, S. J., Tomita, H., Li, J. Z., Vawter, M. P., et al. (2005). Altered cortical glutamatergic and GABAergic signal transmission with glial involvement in depression. Proc. Natl. Acad. Sci. U.S.A. 102, 15653-15658. doi: 10.1073/pnas.0507901102

Cichon, S., Muhleisen, T. W., Degenhardt, F. A., Mattheisen, M., Miro, X., Strohmaier, J., et al. (2011). Genome-wide association study identifies genetic variation in neurocan as a susceptibility factor for bipolar disorder. Am. J. Hum. Genet. 88, 372-381. doi: 10.1016/j.ajhg.2011.01.017

Cirrito, J. R., Disabato, B. M., Restivo, J. L., Verges, D. K., Goebel, W. D., Sathyan, A., et al. (2011). Serotonin signaling is associated with lower amyloid-beta levels and plaques in transgenic mice and humans. Proc. Natl. Acad. Sci. U.S.A. 108, 14968-14973. doi: 10.1073/pnas.1107411108

Conant, K., Allen, M., and Lim, S. T. (2015). Activity dependent CAM cleavage and neurotransmission. Front. Cell. Neurosci. 9:305. doi: 10.3389/fncel.2015.00305

Conant, K., Lonskaya, I., Szklarczyk, A., Krall, C., Steiner, J., Maguire-Zeiss, K., et al. (2011). Methamphetamine-associated cleavage of the synaptic adhesion molecule intercellular adhesion molecule-5. J. Neurochem. 118, 521-532. doi: 10.1111/j.1471-4159.2010.07153.x

Conant, K., St Hillaire, C., Anderson, C., Galey, D., Wang, J., and Nath, A. (2004). Human immunodeficiency virus type 1 Tat and methamphetamine affect the release and activation of matrix-degrading proteinases. J. Neurovirol. 10, 21-28. doi: 10.1080/13550280490261699

Conant, K., Wang, Y., Szklarczyk, A., Dudak, A., Mattson, M. P., and Lim, S. T. (2010). Matrix metalloproteinase-dependent shedding of intercellular adhesion molecule-5 occurs with long-term potentiation. Neuroscience 166, 508-521. doi: 10.1016/j.neuroscience.2009.12.061

Cowen, S. L., Gray, D. T., Wiegand, J. L., Schimanski, L. A., and Barnes, C. A. (2018). Age-associated changes in waking hippocampal sharp-wave ripples. Hippocampus doi: 10.1002/hipo.23005 [Epub ahead of print].

Favuzzi, E., Marques-Smith, A., Deogracias, R., Winterflood, C. M., SanchezAguilera, A., Mantoan, L., et al. (2017). Activity-dependent gating of parvalbumin interneuron function by the perineuronal net protein brevican. Neuron 95, 639-655.e10. doi: 10.1016/j.neuron.2017.06.028

Fenton, E. Y., Fournier, N. M., Lussier, A. L., Romay-Tallon, R., Caruncho, H. J., and Kalynchuk, L. E. (2015). Imipramine protects against the deleterious effects of chronic corticosterone on depression-like behavior, hippocampal reelin expression, and neuronal maturation. Prog. Neuropsychopharmacol. Biol. Psychiatry 60, 52-59. doi: 10.1016/j.pnpbp.2015.02.001 
Fitzgerald, P. J., and Watson, B. O. (2018). Gamma oscillations as a biomarker for major depression: an emerging topic. Transl. Psychiatry 8:177. doi: 10.1038/ s41398-018-0239-y

Fragkouli, A., Papatheodoropoulos, C., Georgopoulos, S., Stamatakis, A., Stylianopoulou, F., Tsilibary, E. C., et al. (2012). Enhanced neuronal plasticity and elevated endogenous sAPPalpha levels in mice over-expressing MMP9. J. Neurochem. 121, 239-251. doi: 10.1111/j.1471-4159.2011.07637.x

Fragkouli, A., Tsilibary, E. C., and Tzinia, A. K. (2014). Neuroprotective role of MMP-9 overexpression in the brain of Alzheimer's 5xFAD mice. Neurobiol. Dis. 70, 179-189. doi: 10.1016/j.nbd.2014.06.021

Frischknecht, R., Heine, M., Perrais, D., Seidenbecher, C. I., Choquet, D., and Gundelfinger, E. D. (2009). Brain extracellular matrix affects AMPA receptor lateral mobility and short-term synaptic plasticity. Nat. Neurosci. 12, 897-904. doi: $10.1038 / \mathrm{nn} .2338$

Ganguly, K., Rejmak, E., Mikosz, M., Nikolaev, E., Knapska, E., and Kaczmarek, L. (2013). Matrix metalloproteinase (MMP) 9 transcription in mouse brain induced by fear learning. J. Biol. Chem. 288, 20978-20991. doi: 10.1074/jbc. M113.457903

Gu, Z., Kaul, M., Yan, B., Kridel, S. J., Cui, J., Strongin, A., et al. (2002). Snitrosylation of matrix metalloproteinases: signaling pathway to neuronal cell death. Science 297, 1186-1190. doi: 10.1126/science.1073634

Guirado, R., Perez-Rando, M., Sanchez-Matarredona, D., Castren, E., and Nacher, J. (2014). Chronic fluoxetine treatment alters the structure, connectivity and plasticity of cortical interneurons. Int. J. Neuropsychopharmacol. 17, 1635-1646. doi: $10.1017 /$ S1461145714000406

Hartmann, D., De Strooper, B., Serneels, L., Craessaerts, K., Herreman, A., Annaert, W., et al. (2002). The disintegrin/metalloprotease ADAM 10 is essential for Notch signalling but not for alpha-secretase activity in fibroblasts. Hum. Mol. Genet. 11, 2615-2624. doi: 10.1093/hmg/11.21.2615

Hayani, H., Song, I., and Dityatev, A. (2018). Increased excitability and reduced excitatory synaptic input into fast-spiking CA2 interneurons after enzymatic attenuation of extracellular matrix. Front. Cell. Neurosci. 12:149. doi: 10.3389/ fncel.2018.00149

He, H. Y., Shen, W., Hiramoto, M., and Cline, H. T. (2016). Experience-dependent bimodal plasticity of inhibitory neurons in early development. Neuron 90, 1203-1214. doi: 10.1016/j.neuron.2016.04.044

Hernandez-Guillamon, M., Mawhirt, S., Blais, S., Montaner, J., Neubert, T. A., Rostagno, A., et al. (2015). Sequential amyloid-beta degradation by the matrix metalloproteases MMP-2 and MMP-9. J. Biol. Chem. 290, 15078-15091. doi: 10.1074/jbc.M114.610931

Hoe, H. S., Cooper, M. J., Burns, M. P., Lewis, P. A., Van Der Brug, M., Chakraborty, G., et al. (2007). The metalloprotease inhibitor TIMP-3 regulates amyloid precursor protein and apolipoprotein E receptor proteolysis. J. Neurosci. 27, 10895-10905. doi: 10.1523/jneurosci.3135-07.2007

Howard, M. W., Rizzuto, D. S., Caplan, J. B., Madsen, J. R., Lisman, J., Aschenbrenner-Scheibe, R., et al. (2003). Gamma oscillations correlate with working memory load in humans. Cereb. Cortex 13, 1369-1374. doi: 10.1093/ cercor/bhg084

Huntley, G. W. (2012). Synaptic circuit remodeling by matrix metalloproteinases in health and disease. Nat. Rev. Neurosci. 13, 743-757. doi: 10.1038/nrn3320

Iaccarino, H. F., Singer, A. C., Martorell, A. J., Rudenko, A., Gao, F., Gillingham, T. Z., et al. (2016). Gamma frequency entrainment attenuates amyloid load and modifies microglia. Nature 540, 230-235. doi: 10.1038/nature20587

Insel, N., Patron, L. A., Hoang, L. T., Nematollahi, S., Schimanski, L. A., Lipa, P., et al. (2012). Reduced gamma frequency in the medial frontal cortex of aged rats during behavior and rest: implications for age-related behavioral slowing. J. Neurosci. 32, 16331-16344. doi: 10.1523/JNEUROSCI.1577-12.2012

Jhaveri, D. J., Mackay, E. W., Hamlin, A. S., Marathe, S. V., Nandam, L. S., Vaidya, V. A., et al. (2010). Norepinephrine directly activates adult hippocampal precursors via beta3-adrenergic receptors. J. Neurosci. 30, 2795-2806. doi: 10. 1523/JNEUROSCI.3780-09.2010

Jorissen, E., Prox, J., Bernreuther, C., Weber, S., Schwanbeck, R., Serneels, L., et al. (2010). The disintegrin/metalloproteinase ADAM10 is essential for the establishment of the brain cortex. J. Neurosci. 30, 4833-4844. doi: 10.1523/ JNEUROSCI.5221-09.2010

Joshi, S. H., Espinoza, R. T., Pirnia, T., Shi, J., Wang, Y., Ayers, B., et al. (2015). Structural plasticity of the hippocampus and amygdala induced by electroconvulsive therapy in major depression. Biol. Psychiatry 79, 282-292. doi: 10.1016/j.biopsych.2015.02.029

Jutras, M. J., and Buffalo, E. A. (2010). Synchronous neural activity and memory formation. Curr. Opin. Neurobiol. 20, 150-155. doi: 10.1016/j.conb.2010. 02.006

Kalinin, S., Gavrilyuk, V., Polak, P. E., Vasser, R., Zhao, J., Heneka, M. T., et al. (2007). Noradrenaline deficiency in brain increases beta-amyloid plaque burden in an animal model of Alzheimer's disease. Neurobiol. Aging 28, 12061214. doi: 10.1016/j.neurobiolaging.2006.06.003

Kasthuri, N., Hayworth, K. J., Berger, D. R., Schalek, R. L., Conchello, J. A., Knowles-Barley, S., et al. (2015). Saturated reconstruction of a volume of neocortex. Cell 162, 648-661. doi: 10.1016/j.cell.2015.06.054

Kean, M. J., Williams, K. C., Skalski, M., Myers, D., Burtnik, A., Foster, D., et al. (2009). VAMP3, syntaxin-13 and SNAP23 are involved in secretion of matrix metalloproteinases, degradation of the extracellular matrix and cell invasion. J. Cell Sci. 122, 4089-4098. doi: 10.1242/jcs.052761

Kessing, L. V., and Nilsson, F. M. (2003). Increased risk of developing dementia in patients with major affective disorders compared to patients with other medical illnesses. J. Affect. Disord. 73, 261-269. doi: 10.1016/s0165-0327(02) 00004-6

Kivipelto, M., Mangialasche, F., and Ngandu, T. (2018). Lifestyle interventions to prevent cognitive impairment, dementia and Alzheimer disease. Nat. Rev. Neurol. 14, 653-666. doi: 10.1038/s41582-018-0070-3

Klein, A. S., Donoso, J. R., Kempter, R., Schmitz, D., and Beed, P. (2016). Early cortical changes in gamma oscillations in Alzheimer's disease. Front. Syst. Neurosci. 10:83. doi: 10.3389/fnsys.2016.00083

Kuhn, M., Mainberger, F., Feige, B., Maier, J. G., Mall, V., Jung, N. H., et al. (2016). State-dependent partial occlusion of cortical LTP-like plasticity in major depression. Neuropsychopharmacology 41, 1521-1529. doi: 10.1038/npp.2015. 310

Kuzniewska, B., Rejmak, E., Malik, A. R., Jaworski, J., Kaczmarek, L., and Kalita, K. (2013). Brain-derived neurotrophic factor induces matrix metalloproteinase 9 expression in neurons via the serum response factor/c-Fos pathway. Mol. Cell. Biol. 33, 2149-2162. doi: 10.1128/MCB.00008-13

Lammich, S., Kojro, E., Postina, R., Gilbert, S., Pfeiffer, R., Jasionowski, M., et al. (1999). Constitutive and regulated alpha-secretase cleavage of Alzheimer's amyloid precursor protein by a disintegrin metalloprotease. Proc. Natl. Acad. Sci. U.S.A. 96, 3922-3927. doi: 10.1073/pnas.96.7.3922

Lee, R., Kermani, P., Teng, K. K., and Hempstead, B. L. (2001). Regulation of cell survival by secreted proneurotrophins. Science 294, 1945-1948. doi: 10.1126/ science. 1065057

Lensjo, K. K., Christensen, A. C., Tennoe, S., Fyhn, M., and Hafting, T. (2017a). Differential expression and cell-type specificity of perineuronal nets in hippocampus, medial entorhinal cortex, and visual cortex examined in the rat and mouse. eNeuro 4:ENEURO.0379-16.2017. doi: 10.1523/ENEURO.0379-16. 2017

Lensjo, K. K., Lepperod, M. E., Dick, G., Hafting, T., and Fyhn, M. (2017b). Removal of perineuronal nets unlocks juvenile plasticity through network mechanisms of decreased inhibition and increased gamma activity. J. Neurosci. 37, 1269-1283. doi: 10.1523/JNEUROSCI.2504-16.2016

Li, B., Yu, D., and $\mathrm{Xu}, \mathrm{Z}$. (2014). Activated protein C inhibits amyloid beta production via promoting expression of ADAM-10. Brain Res. 1545, 35-44. doi: 10.1016/j.brainres.2013.12.005

Li, D., Xiao, Z., Wang, G., and Song, X. (2015). Knockdown of ADAM10 inhibits migration and invasion of fibroblast-like synoviocytes in rheumatoid arthritis. Mol. Med. Rep. 12, 5517-5523. doi: 10.3892/mmr.2015.4011

Li, Y., Partridge, J., Berger, C., Sepulveda-Rodriguez, A., Vicini, S., and Conant, K. (2016). Dopamine increases NMDA-stimulated calcium flux in striatopallidal neurons through a matrix metalloproteinase-dependent mechanism. Eur. J. Neurosci. 43, 194-203. doi: 10.1111/ejn.13146

Lonskaya, I., Partridge, J., Lalchandani, R. R., Chung, A., Lee, T., Vicini, S., et al. (2013). Soluble ICAM-5, a product of activity dependent proteolysis, increases mEPSC frequency and dendritic expression of GluA1. PLoS One 8:e69136. doi: 10.1371/journal.pone.0069136

MacQueen, G., and Frodl, T. (2011). The hippocampus in major depression: evidence for the convergence of the bench and bedside in psychiatric research? Mol. Psychiatry 16, 252-264. doi: 10.1038/mp.2010.80 
Malberg, J. E., Eisch, A. J., Nestler, E. J., and Duman, R. S. (2000). Chronic antidepressant treatment increases neurogenesis in adult rat hippocampus. J. Neurosci. 20, 9104-9110. doi: 10.1523/jneurosci.20-24-09104.2000

Maolood, N., Hardin-Pouzet, H., and Grange-Messent, V. (2008). Matrix metalloproteinases MMP2 and MMP9 are upregulated by noradrenaline in the mouse neuroendocrine hypothalamus. Eur. J. Neurosci. 27, 1143-1152. doi: 10.1111/j.1460-9568.2008.06099.x

Meighan, P. C., Meighan, S. E., Davis, C. J., Wright, J. W., and Harding, J. W. (2007). Effects of matrix metalloproteinase inhibition on short- and long-term plasticity of schaffer collateral/CA1 synapses. J. Neurochem. 102, 2085-2096. doi: 10.1111/j.1471-4159.2007.04682.x

Meighan, S. E., Meighan, P. C., Choudhury, P., Davis, C. J., Olson, M. L., Zornes, P. A., et al. (2006). Effects of extracellular matrix-degrading proteases matrix metalloproteinases 3 and 9 on spatial learning and synaptic plasticity. J. Neurochem. 96, 1227-1241. doi: 10.1111/j.1471-4159.2005.03565.x

Michaluk, P., Kolodziej, L., Mioduszewska, B., Wilczynski, G. M., Dzwonek, J., Jaworski, J., et al. (2007). Beta-dystroglycan as a target for MMP-9, in response to enhanced neuronal activity. J. Biol. Chem. 282, 16036-16041. doi: 10.1074/ jbc.m700641200

Miller, B. R., and Hen, R. (2015). The current state of the neurogenic theory of depression and anxiety. Curr. Opin. Neurobiol. 30, 51-58. doi: 10.1016/j.conb. 2014.08.012

Missan, D. S., Mitchell, K., Subbaram, S., and Dipersio, C. M. (2015). Integrin alpha3betal signaling through MEK/ERK determines alternative polyadenylation of the MMP-9 mRNA transcript in immortalized mouse keratinocytes. PLoS One 10:e0119539. doi: 10.1371/journal.pone.0119539

Mizoguchi, H., Yamada, K., and Nabeshima, T. (2008). Neuropsychotoxicity of abused drugs: involvement of matrix metalloproteinase- 2 and -9 and tissue inhibitor of matrix metalloproteinase- 2 in methamphetamine-induced behavioral sensitization and reward in rodents. J. Pharmacol. Sci. 106, 9-14. doi: 10.1254/jphs.fm0070139

Mizoguchi, H., Yamada, K., Niwa, M., Mouri, A., Mizuno, T., Noda, Y., et al. (2007). Reduction of methamphetamine-induced sensitization and reward in matrix metalloproteinase-2 and -9-deficient mice. J. Neurochem. 100, 1579-1588.

Murase, S., Lantz, C. L., Kim, E., Gupta, N., Higgins, R., Stopfer, M., et al. (2016). Matrix metalloproteinase- 9 regulates neuronal circuit development and excitability. Mol. Neurobiol. 53, 3477-3493. doi: 10.1007/s12035-015-9295-y

Murase, S., Lantz, C. L., and Quinlan, E. M. (2017). Light reintroduction after dark exposure reactivates plasticity in adults via perisynaptic activation of MMP-9. eLife 6:e27345. doi: 10.7554/eLife.27345

Nagy, V., Bozdagi, O., Matynia, A., Balcerzyk, M., Okulski, P., Dzwonek, J., et al. (2006). Matrix metalloproteinase-9 is required for hippocampal latephase long-term potentiation and memory. J. Neurosci. 26, 1923-1934. doi: 10.1523/jneurosci.4359-05.2006

Ohira, K., Takeuchi, R., Iwanaga, T., and Miyakawa, T. (2013). Chronic fluoxetine treatment reduces parvalbumin expression and perineuronal nets in gammaaminobutyric acidergic interneurons of the frontal cortex in adult mice. Mol. Brain 6:43. doi: 10.1186/1756-6606-6-43

Okamoto, T., Akaike, T., Sawa, T., Miyamoto, Y., Van Der Vliet, A., and Maeda, H. (2001). Activation of matrix metalloproteinases by peroxynitrite-induced protein S-glutathiolation via disulfide S-oxide formation. J. Biol. Chem. 276, 29596-29602. doi: 10.1074/jbc.m102417200

Pantazopoulos, H., and Berretta, S. (2016). In sickness and in health: perineuronal nets and synaptic plasticity in psychiatric disorders. Neural Plast. 2016:9847696. doi: 10.1155/2016/9847696

Pauly, T., Ratliff, M., Pietrowski, E., Neugebauer, R., Schlicksupp, A., Kirsch, J., et al. (2008). Activity-dependent shedding of the NMDA receptor glycine binding site by matrix metalloproteinase 3: a PUTATIVE mechanism of postsynaptic plasticity. PLoS One 3:e2681. doi: 10.1371/journal.pone. 0002681

Pizzorusso, T., Medini, P., Berardi, N., Chierzi, S., Fawcett, J. W., and Maffei, L. (2002). Reactivation of ocular dominance plasticity in the adult visual cortex. Science 298, 1248-1251. doi: 10.1126/science.1072699

Py, N. A., Bonnet, A. E., Bernard, A., Marchalant, Y., Charrat, E., Checler, F., et al. (2014). Differential spatio-temporal regulation of MMPs in the 5xFAD mouse model of Alzheimer's disease: evidence for a pro-amyloidogenic role of MT1-MMP. Front. Aging Neurosci. 6:247. doi: 10.3389/fnagi.2014.00247
Rietz, A., and Spiers, J. (2012). The relationship between the MMP system, adrenoceptors and phosphoprotein phosphatases. Br. J. Pharmacol. 166, 12251243. doi: 10.1111/j.1476-5381.2012.01917.x

Riga, D., Kramvis, I., Koskinen, M. K., Van Bokhoven, P., Van Der Harst, J. E., Heistek, T. S., et al. (2017). Hippocampal extracellular matrix alterations contribute to cognitive impairment associated with a chronic depressive-like state in rats. Sci. Transl. Med. 9:eaai8753. doi: 10.1126/scitranslmed.aai8753

Robinson, T. E., and Kolb, B. (2004). Structural plasticity associated with exposure to drugs of abuse. Neuropharmacology 47(Suppl. 1), 33-46. doi: 10.1016/j. neuropharm.2004.06.025

Rossier, J., Bernard, A., Cabungcal, J. H., Perrenoud, Q., Savoye, A., Gallopin, T., et al. (2015). Cortical fast-spiking parvalbumin interneurons enwrapped in the perineuronal net express the metallopeptidases Adamts8, Adamts15 and Neprilysin. Mol. Psychiatry 20, 154-161. doi: 10.1038/mp.2014.162

Sanz, R., Ferraro, G. B., and Fournier, A. E. (2015). IgLON cell adhesion molecules are shed from the cell surface of cortical neurons to promote neuronal growth. J. Biol. Chem. 290, 4330-4342. doi: 10.1074/jbc.M114.628438

Sbai, O., Ferhat, L., Bernard, A., Gueye, Y., Ould-Yahoui, A., Thiolloy, S., et al. (2008). Vesicular trafficking and secretion of matrix metalloproteinases-2, 9 and tissue inhibitor of metalloproteinases-1 in neuronal cells. Mol. Cell Neurosci. 39, 549-568. doi: 10.1016/j.mcn.2008.08.004

Schmidt, M. V., Trumbach, D., Weber, P., Wagner, K., Scharf, S. H., Liebl, C., et al. (2010). Individual stress vulnerability is predicted by short-term memory and AMPA receptor subunit ratio in the hippocampus. J. Neurosci. 30, 16949-16958. doi: 10.1523/JNEUROSCI.4668-10.2010

Schoenfeld, T. J., Mccausland, H. C., Morris, H. D., Padmanaban, V., and Cameron, H. A. (2017). Stress and loss of adult neurogenesis differentially reduce hippocampal volume. Biol. Psychiatry 82, 914-923. doi: 10.1016/j.biopsych. 2017.05.013

Shaywitz, A. J., and Greenberg, M. E. (1999). CREB: a stimulus-induced transcription factor activated by a diverse array of extracellular signals. Annu. Rev. Biochem. 68, 821-861. doi: 10.1146/annurev.biochem.68.1.821

Sheline, Y. I., West, T., Yarasheski, K., Swarm, R., Jasielec, M. S., Fisher, J. R., et al. (2014). An antidepressant decreases CSF Abeta production in healthy individuals and in transgenic AD mice. Sci. Transl. Med. 6:236re4. doi: 10.1126/ scitranslmed.3008169

Skovronsky, D. M., Moore, D. B., Milla, M. E., Doms, R. W., and Lee, V. M. (2000). Protein kinase C-dependent alpha-secretase competes with beta-secretase for cleavage of amyloid-beta precursor protein in the trans-golgi network. J. Biol. Chem. 275, 2568-2575. doi: 10.1074/jbc.275.4.2568

Slaker, M., Churchill, L., Todd, R. P., Blacktop, J. M., Zuloaga, D. G., Raber, J., et al. (2015). Removal of perineuronal nets in the medial prefrontal cortex impairs the acquisition and reconsolidation of a cocaine-induced conditioned place preference memory. J. Neurosci. 35, 4190-4202. doi: 10.1523/JNEUROSCI. 3592-14.2015

Smith, A. C., Kupchik, Y. M., Scofield, M. D., Gipson, C. D., Wiggins, A., Thomas, C. A., et al. (2014). Synaptic plasticity mediating cocaine relapse requires matrix metalloproteinases. Nat. Neurosci. 17, 1655-1657. doi: 10.1038/nn.3846

Sonderegger, P., and Matsumoto-Miyai, K. (2014). Activity-controlled proteolytic cleavage at the synapse. Trends Neurosci. 37, P413-P423. doi: 10.1016/j.tins. 2014.05.007

Stawarski, M., Stefaniuk, M., and Wlodarczyk, J. (2014). Matrix metalloproteinase9 involvement in the structural plasticity of dendritic spines. Front. Neuroanat. 8:68. doi: 10.3389/fnana.2014.00068

Stoiljkovic, M., Kelley, C., Horvath, T. L., and Hajos, M. (2018). Neurophysiological signals as predictive translational biomarkers for Alzheimer's disease treatment: effects of donepezil on neuronal network oscillations in TgF344-AD rats. Alzheimers Res. Ther. 10:105. doi: 10.1186/s13195-018-0433-4

Sullivan, D., Csicsvari, J., Mizuseki, K., Montgomery, S., Diba, K., and Buzsaki, G. (2011). Relationships between hippocampal sharp waves, ripples, and fast gamma oscillation: influence of dentate and entorhinal cortical activity. J. Neurosci. 31, 8605-8616. doi: 10.1523/JNEUROSCI.0294-11.2011

Sun, Z. Y., Bozzelli, P. L., Caccavano, A., Allen, M., Balmuth, J., Vicini, S., et al. (2018). Disruption of perineuronal nets increases the frequency of sharp wave ripple events. Hippocampus 28, 42-52. doi: 10.1002/hipo.22804

Szepesi, Z., Bijata, M., Ruszczycki, B., Kaczmarek, L., and Wlodarczyk, J. (2013). Matrix metalloproteinases regulate the formation of dendritic spine head 
protrusions during chemically induced long-term potentiation. PLoS One 8:e63314. doi: 10.1371/journal.pone.0063314

Tamasi, V., Petschner, P., Adori, C., Kirilly, E., Ando, R. D., Tothfalusi, L., et al. (2014). Transcriptional evidence for the role of chronic venlafaxine treatment in neurotrophic signaling and neuroplasticity including also Glutamatergic [corrected] - and insulin-mediated neuronal processes. PLoS One 9:e113662. doi: 10.1371 /journal.pone.0113662

Tewari, B. P., Chaunsali, L., Campbell, S. L., Patel, D. C., Goode, A. E., and Sontheimer, H. (2018). Perineuronal nets decrease membrane capacitance of peritumoral fast spiking interneurons in a model of epilepsy. Nat. Commun. 9:4724. doi: 10.1038/s41467-018-07113-0

Thompson, P. M., Andreassen, O. A., Arias-Vasquez, A., Bearden, C. E., Boedhoe, P. S., Brouwer, R. M., et al. (2015). ENIGMA and the individual: predicting factors that affect the brain in 35 countries worldwide. Neuroimage 145(Pt B), 389-408. doi: 10.1016/j.neuroimage.2015.11.057

Thompson, S. M., Kallarackal, A. J., Kvarta, M. D., Van Dyke, A. M., Legates, T. A., and Cai, X. (2015). An excitatory synapse hypothesis of depression. Trends Neurosci. 38, 279-294. doi: 10.1016/j.tins.2015.03.003

Tian, L., Stefanidakis, M., Ning, L., Van Lint, P., Nyman-Huttunen, H., Libert, C., et al. (2007). Activation of NMDA receptors promotes dendritic spine development through MMP-mediated ICAM-5 cleavage. J. Cell Biol. 178, 687700. doi: $10.1083 /$ jcb.200612097

Toth, M., Chvyrkova, I., Bernardo, M. M., Hernandez-Barrantes, S., and Fridman, R. (2003). Pro-MMP-9 activation by the MT1-MMP/MMP-2 axis and MMP-3: role of TIMP-2 and plasma membranes. Biochem. Biophys. Res. Commun. 308, 386-395. doi: 10.1016/s0006-291x(03)01405-0

Umemori, J., Winkel, F., Castren, E., and Karpova, N. N. (2015). Distinct effects of perinatal exposure to fluoxetine or methylmercury on parvalbumin and perineuronal nets, the markers of critical periods in brain development. Int. J. Dev. Neurosci. 44, 55-64. doi: 10.1016/j.ijdevneu.2015.05.006

van der Vorst, E. P., Jeurissen, M., Wolfs, I. M., Keijbeck, A., Theodorou, K., Wijnands, E., et al. (2015). Myeloid A disintegrin and metalloproteinase domain 10 deficiency modulates atherosclerotic plaque composition by shifting the balance from inflammation toward fibrosis. Am. J. Pathol. 185, 1145-1155. doi: 10.1016/j.ajpath.2014.11.028

Verslegers, M., Van Hove, I., Dekeyster, E., Gantois, I., Hu, T. T., D’hooge, R., et al. (2015). MMP-2 mediates Purkinje cell morphogenesis and spine development in the mouse cerebellum. Brain Struct. Funct. 220, 1601-1617. doi: 10.1007/ s00429-014-0747-3

Wan, X. Z., Li, B., Li, Y. C., Yang, X. L., Zhang, W., Zhong, L., et al. (2012). Activation of NMDA receptors upregulates a disintegrin and metalloproteinase 10 via a Wnt/MAPK signaling pathway. J. Neurosci. 32, 3910-3916. doi: 10. 1523/JNEUROSCI.3916-11.2012

Wang, X. B., Bozdagi, O., Nikitczuk, J. S., Zhai, Z. W., Zhou, Q., and Huntley, G. W. (2008). Extracellular proteolysis by matrix metalloproteinase-9 drives dendritic spine enlargement and long-term potentiation coordinately. Proc. Natl. Acad. Sci. U.S.A. 105, 19520-19525. doi: 10.1073/pnas.0807248105

Wen, T. H., Afroz, S., Reinhard, S. M., Palacios, A. R., Tapia, K., Binder, D. K., et al. (2017). Genetic reduction of matrix metalloproteinase-9 promotes formation of perineuronal nets around parvalbumin-expressing interneurons and normalizes auditory cortex responses in developing Fmr1 knock-out mice. Cereb. Cortex 28, 3951-3964. doi: 10.1093/cercor/bhx258

Widman, A. J., and McMahon, L. L. (2018). Disinhibition of CA1 pyramidal cells by low-dose ketamine and other antagonists with rapid antidepressant efficacy. Proc. Natl. Acad. Sci. U.S.A. 115, E3007-E3016. doi: 10.1073/pnas.1718883115

Wiera, G., Nowak, D., Van Hove, I., Dziegiel, P., Moons, L., and Mozrzymas, J. W. (2017). Mechanisms of NMDA receptor- and voltage-gated L-type calcium channel-dependent hippocampal LTP critically rely on proteolysis that is mediated by distinct metalloproteinases. J. Neurosci. 37, 1240-1256. doi: 10 . 1523/JNEUROSCI.2170-16.2016

Wiera, G., Wojtowicz, T., Lebida, K., Piotrowska, A., Drulis-Fajdasz, D., Gomulkiewicz, A., et al. (2012). Long term potentiation affects intracellular metalloproteinases activity in the mossy fiber-CA3 pathway. Mol. Cell. Neurosci. 50, 147-159. doi: 10.1016/j.mcn.2012.04.005

Wojtowicz, T., and Mozrzymas, J. W. (2014). Matrix metalloprotease activity shapes the magnitude of EPSPs and spike plasticity within the hippocampal CA3 network. Hippocampus 24, 135-153. doi: 10.1002/hipo.22205

Xie, S., Price, J. E., Luca, M., Jean, D., Ronai, Z., and Bar-Eli, M. (1997). Dominantnegative CREB inhibits tumor growth and metastasis of human melanoma cells. Oncogene 15, 2069-2075. doi: 10.1038/sj.onc.1201358

Yang, E. V., Sood, A. K., Chen, M., Li, Y., Eubank, T. D., Marsh, C. B., et al. (2006). Norepinephrine up-regulates the expression of vascular endothelial growth factor, matrix metalloproteinase (MMP)-2, and MMP-9 in nasopharyngeal carcinoma tumor cells. Cancer Res. 66, 10357-10364. doi: 10.1158/0008-5472. can-06-2496

Zanos, P., Nelson, M. E., Highland, J. N., Krimmel, S. R., Georgiou, P., Gould, T. D., et al. (2017). A Negative allosteric modulator for alpha5 subunitcontaining GABA receptors exerts a rapid and persistent antidepressant-like action without the side effects of the NMDA receptor antagonist ketamine in mice. eNeuro 4:ENEURO.0285-16.2017. doi: 10.1523/ENEURO.028516.2017

Zarate, C. A. Jr., Singh, J. B., Carlson, P. J., Brutsche, N. E., Ameli, R., Luckenbaugh, D. A., et al. (2006). A randomized trial of an N-methyl-D-aspartate antagonist in treatment-resistant major depression. Arch. Gen. Psychiatry 63, 856-864.

Zarnadze, S., Bauerle, P., Santos-Torres, J., Bohm, C., Schmitz, D., Geiger, J. R., et al. (2016). Cell-specific synaptic plasticity induced by network oscillations. eLife 5:e14912. doi: 10.7554/eLife.14912

Conflict of Interest Statement: The authors declare that the research was conducted in the absence of any commercial or financial relationships that could be construed as a potential conflict of interest.

Copyright (c) 2019 Alaiyed and Conant. This is an open-access article distributed under the terms of the Creative Commons Attribution License (CC BY). The use, distribution or reproduction in other forums is permitted, provided the original author(s) and the copyright owner(s) are credited and that the original publication in this journal is cited, in accordance with accepted academic practice. No use, distribution or reproduction is permitted which does not comply with these terms. 